The INL is a

U.S. Department of Energy

National Laboratory

operated by

Battelle Energy Alliance

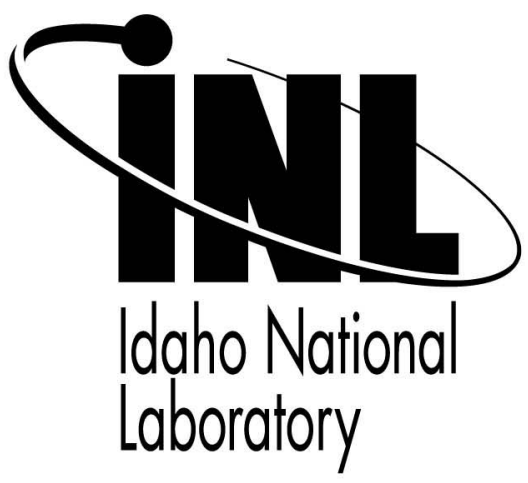

\title{
Theoretical Design of Thermosyphon for Process Heat Transfer from NGNP to Hydrogen Plant
}

\section{ASME $4^{\text {th }}$ International Topical Meeting on High Temperature Reactor Technology}

Piyush Sabharwall

Mike Patterson

Fred Gunnerson

September 2008

This is a preprint of a paper intended for publication in a journal or proceedings. Since changes may be made before publication, this preprint should not be cited or reproduced without permission of the author. This document was prepared as an account of work sponsored by an agency of the United States Government. Neither the United States Government nor any agency thereof, or any of their employees, makes any warranty, expressed or implied, or assumes any legal liability or responsibility for any third party's use, or the results of such use, of any information, apparatus, product or process disclosed in this report, or represents that its use by such third party would not infringe privately owned rights. The views expressed in this paper are not necessarily those of the United States Government or the sponsoring agency. 
HTR2008-58199

\section{THEORETICAL DESIGN OF THERMOSYPHON FOR PROCESS HEAT TRANSFER FROM NGNP TO HYDROGEN PLANT}

\author{
Piyush Sabharwall \\ Nuclear Engineering Program, \\ University of Idaho, Idaho Falls, Idaho, USA
}

\author{
Mike Patterson \\ Idaho National Laboratory \\ Idaho Falls, Idaho, USA
}

\author{
Fred Gunnerson \\ Nuclear Engineering Program \\ University of Idaho, Idaho Falls, \\ Idaho, USA
}

\begin{abstract}
The Next Generation Nuclear Plant (NGNP) will most likely produce electricity and process heat, with both being considered for hydrogen production. To capture nuclear process heat, and transport it to a distant industrial facility requires a high temperature system of heat exchangers, pumps and/or compressors. The heat transfer system is particularly challenging not only due to the elevated temperatures (up to $1300 \mathrm{~K})$ and industrial scale power transport $(\geq 50 \mathrm{MW})$, but also due to a potentially large separation distance between the nuclear and industrial plants $(100+\mathrm{m})$ dictated by safety and licensing mandates.
\end{abstract}

The work reported here is the preliminary analysis of twophase thermosyphon heat transfer performance with alkali metals. A thermosyphon is a device for transporting heat from one point to another with quite extraordinary properties. In contrast to single-phased forced convective heat transfer via 'pumping a fluid', a thermosyphon (also called a wickless heat pipe) transfers heat through the vaporization / condensing process. The condensate is further returned to the hot source by gravity, i.e. without any requirement of pumps or compressors. With this mode of heat transfer, the thermosyphon has the capability to transport heat at high rates over appreciable distances, virtually isothermally and without any requirement for external pumping devices. Two-phase heat transfer by a thermosyphon has the advantage of high enthalpy transport that includes the sensible heat of the liquid, the latent heat of vaporization, and vapor superheat. In contrast, single-phase forced convection transports only the sensible heat of the fluid.
Additionally, vapor-phase velocities within a thermosyphon are much greater than single-phase liquid velocities within a forced convective loop. Thermosyphon performance can be limited by the sonic limit (choking) of vapor flow and/or by condensate entrainment. Proper thermosyphon requires analysis of both.

Keywords: thermosyphon, NGNP, process heat, hydrogen production

\section{INTRODUCTION}

Modern technological developments in the field of nuclear reactors and their process heat application have created renewed interest in the field of alkali metal heat transfer. The application of nuclear power plants as a source of process heat has received national interest because of better economics without greenhouse gases. The Next Generation Nuclear Plant (NGNP) will most likely be producing electricity and process heat, used for hydrogen production. The process heat applicability is not restricted to hydrogen production, but also various other technologies such as extraction of iron ore, coal gasification, liquefactions, and enhanced oil recovery etc. For process heat, a thermal device is needed in order to transfer the thermal energy from the NGNP to the hydrogen plant in the most efficient way possible. A proposed conceptual schematic of an advanced nuclear reactor coupled to a hydrogen production plant is shown in Fig.1. The high temperature gas cooled reactor (HTGR) supplies thermal energy to drive a Brayton power cycle and likewise provide process heat for either high temperature electrolysis (HTE) or for thermochemical sulfur iodine (SI) hydrogen production process. Prismatic and Pebble bed advanced gas cooled 
reactors are the primary reactors being considered in providing the process heat for hydrogen production. In this design, the primary helium coolant is heated in the reactor to outlet temperatures in the range from $1100 \mathrm{~K}$ to $1300 \mathrm{~K}$. A portion of the hot helium outlet stream serves as the working fluid in a gas-turbine power cycle, and a separate helium stream flows through a high temperature heat exchanger, providing process heat to hydrogen production plant. The overall efficiency of electrolytic hydrogen production can be improved by conducting the electrolysis of water vapor at high temperature which reduces electrical energy requirements when compared to conventional cold electrolysis. The thermochemical sulfur iodine (SI) cycle uses thermal energy directly, avoiding the thermal to electrical energy conversion, and is potentially more attractive as a process alternative for hydrogen production. Both the HTE and the SI process are in the early stages of development, however, transfer of thermal energy (heat), and electricity, from the NGNP to the hydrogen production facility is required for either of the processes.

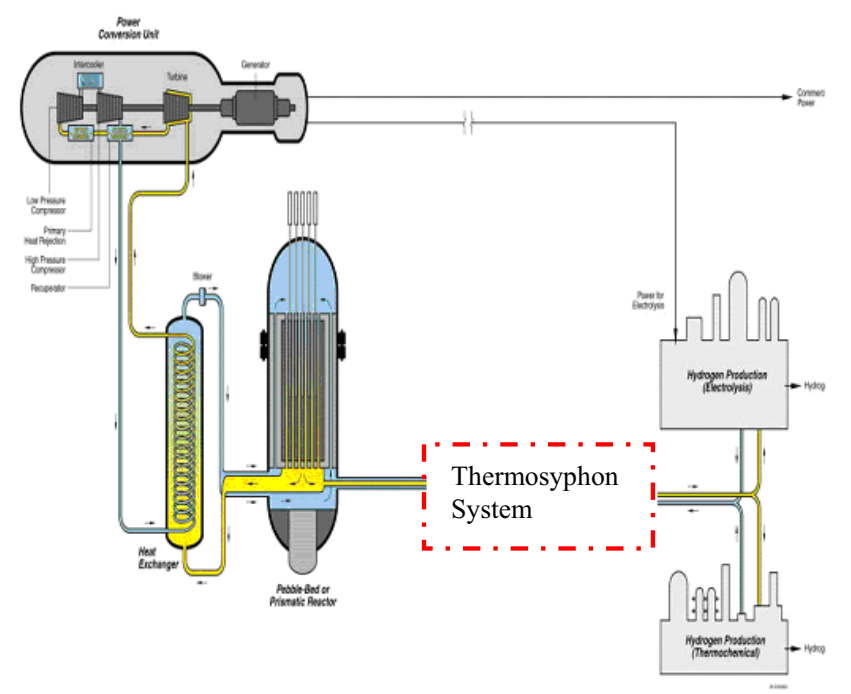

Fig.1 NGNP proposed conceptual schematic of process heat transfer with thermosyphon modified from [1]

\section{THERMOSYPHON SYSTEM}

Figure 2 illustrates a traditional two-phase, closed thermosyphon which is a metal pipe with a fixed amount of working fluid sealed inside. During operation, heat is added to the bottom section (evaporator) and the working fluid becomes vapor. The vapor travels through the middle section (adiabatic section) to the top section (condenser) of the tube. In the condenser, the vapor releases the latent heat and becomes liquid. In contrast to a heat pipe which utilizes capillary forces for liquid return, the thermosyphon relies on gravitational or centrifugal force to return the condensed liquid to the evaporator. The condensed liquid can also be returned to the evaporator through a separate condensate return line.

Heat transfer performance of the thermosyphon is a function of many factors including the thermo-physical properties of the working fluid, geometry and orientation of the thermosyphon, gravity field and operating temperature or pressure. Fundamental heat transfer theory dictates that any mode of heat transfer is driven by a temperature difference and the larger the temperature difference, the higher the heat transfer rate. However, in many applications, it is desirable to transport large amount of heat over a long distance but at a relatively small temperature difference. Inside an operating thermosyphon, the vapor (at or above saturation temperature) carries a large amount of latent heat and vapor super heat from the evaporator to the condenser. One of the most significant advantages of the thermosyphon heat transfer is the characteristic of nearly isothermal phase change heat transfer, which makes the two-phase thermosyphon an ideal candidate for applications where the temperature gradient is limited, such as in the case of a thermochemical hydrogen production facility.

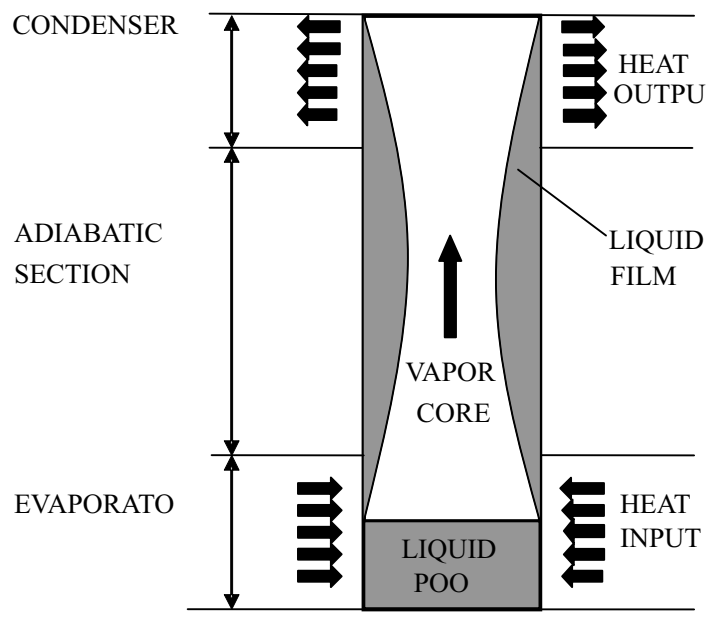

Fig. 2 Regions of typical two-phase closed thermosyphon

\subsection{Working Fluids}

Depending on the temperature and pressure of operation, favorable coolants can be identified. In this analysis we have considered alkaline metals mainly because of their high latent heat and cost. Lithium (Li) is the rarest alkali metal, with the exception of cesium. It is the least dense of the normally solid elements, and is most reactive of the alkali metals. Lithium offers interesting characteristics as a heat-transfer fluid in hightemperature systems. It is the lightest known pure metal and has a comparatively high conductivity, high specific heat, a high boiling point, and a moderately low melting point. Its low density permits high fluid velocities without encountering high 
pressure drop in the system. In our analysis Li is discarded as a high temperature fluid as its boiling point is higher than the operational temperature $(1300 \mathrm{~K})$ of the thermosyphon and its chemical incompatibility with thermosyphon pipe materials. A sub-atmospheric operation pressure would be needed for $\mathrm{Li}$ at NGNP temperatures. Sodium, has a comparatively high conductivity, high specific heat, a high boiling point, and a moderately low melting point. Sodium reacts vigorously with halogens, acidic oxides, and mercury, and alloys with lead, tin, zinc, and bismuth. Potassium (K) reacts similarly to sodium with the exception that, in general, potassium is more reactive [2]. Cesium (Cs) is the most electropositive of all the metals and has a high specific gravity but has a lower latent heat when compared with other alkaline materials. Thermo-physical properties of all the alkaline materials are given in Table 1.

Table 1 Properties of alkali metals [2]

\begin{tabular}{|c|c|c|c|c|c|}
\hline Working Fluids & Melting Temperature $(\mathrm{K})$ & Boiling Temperature $(\mathrm{K})$ & $\mathrm{h}_{\mathrm{fg}}(\mathrm{kJ} / \mathrm{kg}, 1300 \mathrm{~K})$ & $\rho\left(\mathrm{kg} / \mathrm{m}^{3}, 1300 \mathrm{~K}\right)$ & Comments \\
\hline $\mathrm{Li}$ & 452 & 1590 & 20969 & $4.44 \mathrm{E}-03$ & Least favorable \\
\hline $\mathrm{Na}$ & 371 & 1156 & 3790 & $7.79 \mathrm{E}-01$ & Most favorable \\
\hline $\mathrm{K}$ & 337 & 1033 & 1747 & 3.06 & Favorable \\
\hline $\mathrm{Cs}$ & 301 & 978 & 425 & 17.73 & Less Favorable \\
\hline
\end{tabular}

\subsection{Thermal transport Limitation}

A thermosyphon is a very high thermal conductance device but it does possess limitations governed by principles of heat transfer and fluid mechanics. Depending upon conditions the heat transport may be limited by one of the following:

\section{Sonic limit (choking) of vapor flow}

After continuum flow is established, the pressure in the evaporator accelerates the vapor until it reaches a maximum velocity at the evaporator exit. The maximum vapor velocity which can exist at the evaporator exit corresponds to Mach 1. The low downstream vapor pressure of a liquid metal thermosyphon during startup can lead to a sonic vapor velocity at the evaporator exit. The limitation of such flow is similar to converging-diverging nozzle with constant mass flow rate, where the evaporator exit corresponds to the nozzle throat. This choked flow condition is a fundamental limit on the axial vapor flow in a thermosyphon. The axial heat flux at the sonic limit is obtained by calculating the mass flow rate at Mach 1 :

$$
\begin{aligned}
& \frac{\mathrm{Q}_{1}}{\mathrm{~A}_{\mathrm{V}}}=\rho_{\mathrm{v}} \mathrm{h}_{\mathrm{fg}} \mathrm{V}_{\mathrm{S}} \\
& \mathrm{V}_{\mathrm{S}}=\frac{1}{\sqrt{\rho_{\mathrm{v}} \beta_{\mathrm{S}}}}
\end{aligned}
$$

In this analysis the sonic value for $\mathrm{Na}$ vapor $[757 \mathrm{~m} / \mathrm{sec}]$ used is from [3]. At, the sonic limit, the mass flow rate per unit area and the corresponding axial heat flux depend only on the properties of the working fluid and in turn the operating temperature. A closed-form relation for the sonic limit heat transfer rate can be obtained if a uniform evaporation rate is assumed [3]:

$$
\frac{\mathrm{Q}_{1}}{\mathrm{~A}_{\mathrm{v}}}=\frac{\rho \mathrm{h}_{\mathrm{fg}} \mathrm{V}_{\mathrm{s}}}{(2(\gamma+1))^{0.5}}
$$

This limitation is similar to the viscous limitation in that it is typically encountered during the start up transient but does not represent the failure of the system.

\section{Viscous limit}

At very low temperatures for liquid metals, the vapor pressure difference between the evaporator and the condenser is very small. In such cases, the viscous forces may be larger than the vapor pressure gradients and thus prevent vapor flow. This condition is the viscous limitation. It is a function of thermosyphon dimensions and vapor conditions in the evaporator [3]:

$\mathrm{Q}_{1}=\frac{\mathrm{A}_{\mathrm{v}} \mathrm{D}_{\mathrm{v}}^{2} \mathrm{~h}_{\mathrm{fg}} \rho_{0} \mathrm{P}_{0}}{64 \mu \mathrm{L}}$

The vapor pressure of a given working fluid plays a salient role in determination of the maximum distance that will be possible between the nuclear plant and the hydrogen plant. The distance between the nuclear plant and the process plant is directly proportional to the operating temperature and thermal properties of the working fluid, specifically the vapor pressure of the fluid. Higher the vapor pressure longer is the thermosyphon, thus more separation distance is possible between the nuclear and process heat plant.

\subsection{Mass Flow Rate and Sonic Velocity Analysis}

A thermosyphon can transport comparable amounts of thermal energy as a single-phase convective loop, within the same diameter pipe. The ideal rate of convective heat transport through a pipe without losses; modeled in terms of enthalpy can be written as:

$Q^{\prime \prime}=\Delta \mathrm{h} \rho \mathrm{V}=\frac{\dot{\mathrm{m}}}{\mathrm{A}} \Delta \mathrm{h}$ 
Two-phase heat transfer by a thermosyphon has the advantage of high enthalpy transport that includes the sensible heat of the liquid, the latent heat of vaporization, and possible vapor superheat. In contrast, single-phase forced convection transports only the sensible heat of the fluid. Additionally, vapor-phase velocities within a thermosyphon can be much greater than single-phase liquid velocities within a forced convective loop.

$$
\begin{aligned}
& Q^{\prime \prime}=\frac{\dot{\mathrm{m}}}{\mathrm{A}} C_{P, L} \Delta T_{L} \quad \text { (single phase) } \\
& \mathrm{Q}^{\prime \prime}=\frac{\dot{\mathrm{m}}}{\mathrm{A}}(\underbrace{\mathrm{C}_{\mathrm{P}, \mathrm{L}} \Delta \mathrm{T}_{\text {liquid }}}_{\text {Sensible heat of the liquid }}+\mathrm{h}_{\mathrm{fg}}+\underbrace{\mathrm{C}_{\mathrm{P}, \mathrm{V}} \Delta \mathrm{T}_{\text {Vapor }}}_{\text {Vapor Superheat }})
\end{aligned}
$$

Q is assumed to be $50 \mathrm{MW}$ (process heat from NGNP for hydrogen production), and the necessary mass flow rate for all the different alkali metal is compared from the following expression:

$$
\dot{\mathrm{m}}=\frac{\mathrm{Q}}{\mathrm{C}_{\mathrm{P}, \mathrm{L}} \Delta \mathrm{T}_{\text {liquid }}+\mathrm{h}_{\mathrm{fg}}+\mathrm{C}_{\mathrm{P}, \mathrm{V}} \Delta \mathrm{T}_{\text {Vapor }}}
$$

where,

$$
\begin{aligned}
& \Delta \mathrm{T}_{\text {Liquid }}=\mathrm{T}_{\text {boiling }}-\mathrm{T}_{\text {inlet }} \\
& \Delta \mathrm{T}_{\text {Vapor }}=\mathrm{T}_{\text {outlet }}-\mathrm{T}_{\text {boiling }}
\end{aligned}
$$

From Table 1, Li can be discarded as the potential working fluid as it does not boil until $1590 \mathrm{~K}$ at atmospheric pressure, and we desire to operate the thermosyphon at $1300 \mathrm{~K}$. Li is also discarded from consideration by virtue of its high chemical reactivity with Ni alloys; likely material for thermosyphon.

Figure 3 shows the mass flow rate of the alkali metals for heat supply of $50 \mathrm{MW}$, respectively.

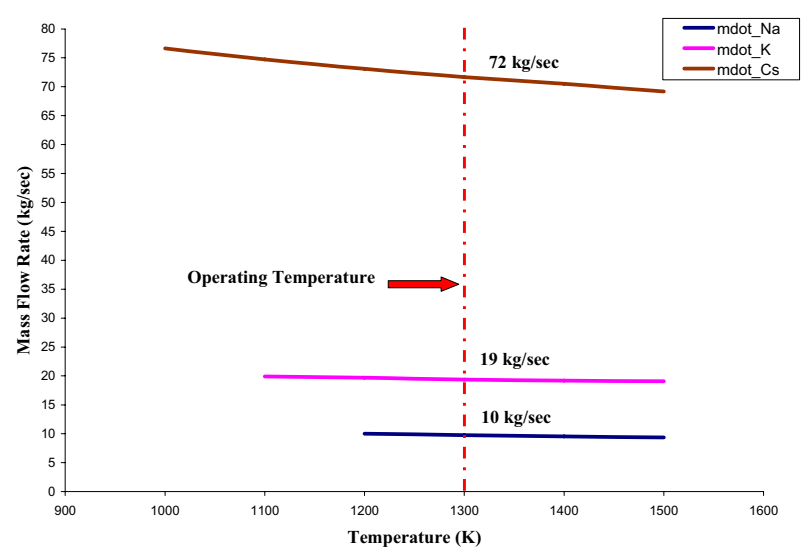

Fig.3 Vapor mass flow rates of different alkali metals for heat transport of $50 \mathrm{MW}$

\section{ALKALI METALS THERMOSYPHON COMPARISON WITH CONVECTIVE LOOP}

Alkali metal thermosyphons and alkali metal forced convective loops can both deliver comparable rates of heat transfer through a given size pipe. This can be easily demonstrated by considering the ideal rate of convective heat transport through a pipe without losses; modeled in terms of enthalpy by:

$$
Q^{\prime \prime}=\Delta \mathrm{h} \rho \mathrm{V}
$$

Two-phase heat transfer by a thermosyphon has the advantage of high enthalpy transport that includes the sensible heat of the liquid, the latent heat of vaporization, and possible vapor superheat, as can be seen from equation (7). In contrast, singlephase forced convection transports only the sensible heat of the fluid. Additionally, vapor-phase velocities within a thermosyphon can be much greater than single-phase liquid velocities within a forced convective loop.

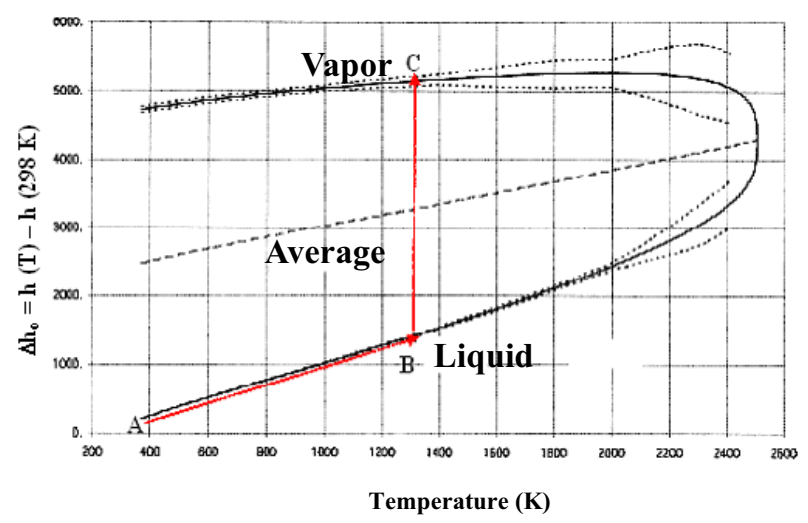

Fig.4 Enthalpy for saturated sodium: liquid and vapor [4]

Figure 4 exemplifies the enthalpy enhancement in heat transfer afforded by a two-phase thermosyphon verses a single-phase convective loop with sodium as the working fluid. The specific enthalpy $(\Delta \mathrm{h})$ of saturated liquid and vapor, relative to the solid at $298.15 \mathrm{~K}$, are illustrated as a function of temperature. Assuming heat transfer from a high-temperature gas cooled reactor at $1300 \mathrm{~K}$ to an industrial facility; the maximum singlephase heat transfer is given by the enthalpy from points A to B in Fig. 4, or approximately 1,200 kJ for each kilogram of sodium. Compare with two-phase heat transfer from points A to $\mathrm{B}$ to $\mathrm{C}$ where the enthalpy gain is approximately $3,790 \mathrm{~kJ}$ per kilogram with no vapor superheat; over 3 times more heat per kilogram of sodium than the single-phase. The saturation pressure of sodium at $1300 \mathrm{~K}$ is only $0.326 \mathrm{MPa}$ thus pressure forces are minimized. Vapor flow through a pipe is limited by compressible 'choke flow' when the vapor reaches its sonic velocity. For sodium vapor the sonic velocity is approximately $757 \mathrm{~m} / \mathrm{sec}$ at $1300 \mathrm{~K}[5]$. 
The limiting heat transfer rate for an ideal sodium thermosyphon operating around $1300 \mathrm{~K}$ can therefore be estimated by equation (9):

$$
\begin{aligned}
\mathrm{Q}^{\prime \prime}=\Delta \mathrm{h} \rho \mathrm{V} & =(3,790) \mathrm{kJ} / \mathrm{kg}(0.8) \mathrm{kg} / \mathrm{m}^{3}(757) \mathrm{m} / \mathrm{s} \\
& =2295 \mathrm{MW} / \mathrm{m}^{2}
\end{aligned}
$$

Similarly, single-phase liquid sodium could transport the same rate of thermal energy with an average flow velocity of about $3.7 \mathrm{~m} / \mathrm{s}$, well within the capabilities of advanced liquid metal pumps. This simple analysis for sodium as the working fluid theoretically illustrates that a thermosyphon and a forced convective loop can both deliver comparable rates of heat transfer through a comparable diameter pipe. An inclined thermosyphon, however, has the luxury of controllable heat transfer without the need for high temperature pumping and can deliver the heat at the same approximate temperature as the source.

\section{CONCLUSIONS}

The success of the next generation of nuclear reactor will depend in part upon the correct selection of process heat transport devices. For high temperature applications requiring transport of large amount of thermal power from a nuclear reactor, at a small temperature difference between the heat source and the heat sink, thermosyphon is a possible choice. The latent heat of vaporization of a liquid metal working fluid is very high, which in turn makes it a preferable choice for transporting high thermal energy. High power throughputs are possible with $\mathrm{Na}$ and considered to be the best with an enthalpy gain of almost 3.5 times compared to single phase. Although considerable data already exists on the thermo-physical properties of possible working fluids, data is rarely available at the high temperatures of NGNP.

High temperature data is clearly needed not only to delineate stable and unstable regions of operations, but also to guide the analyst in the construction of models for the prediction of steady-state and transient system behavior. Accurate performance predictions of liquid metal thermosyphon startup behavior is required to build reliable and efficient thermal control systems for high temperature process heat transfer from NGNP to hydrogen plant.

\section{NOMENCLATURE}

$$
\begin{array}{ll}
\text { A } & \text { Cross-Sectional Flow Area }\left[\mathrm{m}^{2}\right] \\
\mathrm{C}_{\mathrm{P}} & \text { Heat Capacity }\left[\mathrm{kJ} \mathrm{kg}^{-1} \mathrm{~K}^{-1}\right] \\
\mathrm{D} & \text { Diameter }[\mathrm{m}]
\end{array}
$$

$\Delta \mathrm{h} \quad$ Specific Enthalpy Change of the Transport Fluid $\left[\mathrm{kJkg}^{-1}\right]$

\author{
h $\quad$ Enthalpy $\left[\mathrm{kJkg}^{-1}\right]$ \\ $\mathrm{h}_{\mathrm{fg}} \quad$ Latent Heat of Vaporization $\left[\mathrm{kJkg}^{-1}\right]$ \\ L Length of the heat pipe/thermosyphon [m] \\ $\dot{m} \quad$ Mass Flow Rate $\left[\mathrm{kgs}^{-1}\right]$ \\ P Pressure $[\mathrm{MPa}]$ \\ $\mathrm{Q}_{1} \quad$ Axial Heat Flow Rate [W] \\ Q $\quad$ Rate of thermal energy transport per unit flow area \\ $\left[\mathrm{kJm}^{-2} \mathrm{~s}^{-1}\right]$ \\ $\mathrm{T} \quad$ Temperature $[\mathrm{K}]$ \\ V Average Flow Velocity $\left[\mathrm{ms}^{-1}\right]$ \\ Vs Sonic Velocity $\left[\mathrm{ms}^{-1}\right]$ \\ Greek Symbols \\ $\beta_{\mathrm{S}} \quad$ Vapor Adiabatic Compressibility $\left[\mathrm{MPa}^{-1}\right]$ \\ $\rho \quad$ Density $\left[\mathrm{kg} \mathrm{m}^{-3}\right]$ \\ $\gamma \quad$ Ratio of Specific Heat \\ $\mu \quad$ Dynamic Viscosity [ $\left.\mathrm{N} \mathrm{sec} \mathrm{m}^{-2}\right]$ \\ $\Delta \quad$ Difference
}

$\begin{array}{ll}\text { Subscripts } \\ 0 & \text { Stagnation properties (in evaporator) } \\ \mathrm{L} & \text { Liquid } \\ \mathrm{Na} & \text { Sodium } \\ \mathrm{V} & \text { Vapor }\end{array}$

\section{ACKNOWLEDGMENTS}

The funding was provided under the contract DE-AC0705ID14517 project "Next Generation Nuclear Plant", supported by the Idaho National Laboratory. We would like to thank Kevan Weaver and Vivek Utgikar for providing positive reinforcement for our efforts during this study. 


\section{REFERENCES}

[1] NGNP Preliminary Project Plan, June 2007. Document ID: PLN-2489.

[2] Lyon, R.N., et al., 1952, "Liquid Metals Handbook", The Committee on the Basic Properties of Liquid Metals, Office of Naval Research, Department of Navy, $2^{\text {nd }}$ edition.

[3] Dickinson, T., 1996, "Performance Analysis of a Liquid Metal Heat Pipe Space Shuttle Experiment”, Master's Thesis, Air-Force Institute of Technology, Ohio.

[4] Gunnerson,F., Sabharwall,P., and Sherman,S., 2007, "Comparison of Sodium Thermosyphon with Convective Loop", Proceedings of the 2007 AIChE Conference, Salt Lake City.

[5] Bystrov, P.V., Kagan, D.N., Krechetova, G.A. and Shpilrain, E.E., 1990, "Liquid-Metal Coolants for Heat Pipes and Power Plants", Hemisphere Publishing Corporation. 